\title{
Indicators of the relative availability of healthy versus unhealthy foods in supermarkets: a validation study
}

\author{
Stefanie Vandevijvere ${ }^{1 *}$, Tara Mackenzie ${ }^{1}$ and Cliona Ni Mhurchu $^{2}$
}

\begin{abstract}
Background: In-store availability of healthy and unhealthy foods may influence consumer purchases. Methods used to measure food availability, however, vary widely. A simple, valid, and reliable indicator to collect comparable data on in-store food availability is needed.

Methods: Cumulative linear shelf length of and variety within 22 healthy and 28 unhealthy food groups, determined based on a comparison of three nutrient profiling systems, were measured in 15 New Zealand supermarkets. Inter-rater reliability was tested in one supermarket by a second researcher. The construct validity of five simple indicators of relative availability of healthy versus unhealthy foods was assessed against this 'gold standard'.

Results: Cumulative linear shelf length was a more sensitive and feasible measure of food availability than variety. Four out of five shelf length ratio indicators were significantly associated with the gold standard $(\rho=0.70-0.75)$. Based on a non-significant difference from the 'gold standard' $(d=0.053 \pm 0.040)$ and feasibility, the ratio of cumulative linear shelf length of fresh and frozen fruits and vegetables versus soft and energy drinks, crisps and snacks, sweet biscuits and confectionery performed best for use in New Zealand supermarkets.

Conclusions: Four out of the five shelf length ratio indicators of the relative availability of healthy versus unhealthy foods in-store tested could be used for future research and monitoring, but additional validation studies in other settings and countries are recommended. Consistent use of those shelf length ratio indicators could enhance comparability of supermarket food availability between studies, and help inform policies to create healthy consumer food retail environments.
\end{abstract}

Keywords: Consumer retail food environments, INFORMAS, Shelf length, Food variety, Food availability, Supermarkets, Validation

\section{Background}

Overweight and obesity are increasing in many countries globally [1]. A main driver of obesity is unhealthy food environments [2]. Individual behaviours are difficult to change, and interventions targeted at the individual have shown limited effectiveness at a high cost [3]. In contrast, structural interventions on environments can be cost saving, but are more challenging to implement.

Glanz defines the consumer food environment as that which customers encounter when buying food, including

\footnotetext{
* Correspondence: s.vandevijvere@auckland.ac.nz

${ }^{1}$ School of Population Health, The University of Auckland, Private bag 92019,

Glen Innes, New Zealand

Full list of author information is available at the end of the article
}

the cost, quality, and availability of food [4]. There is a growing body of research on consumer retail food environments, which are considered influential on food purchases, dietary behaviours and associated health outcomes $[5,6]$. The relative availability of healthy versus unhealthy foods in-store is an important feature of consumer retail food environments. Systematic reviews evaluating associations between consumer retail food environments and dietary habits have however shown mixed results to date [5-7], due to the large heterogeneity in methods used $[4,5,7]$.

There are six different ways in-store food availability has been measured in previous studies: 1) presence or absence, 2) linear shelf length, 3) proportion of shelf space, 4) shelf surface area, 5) number of displays and 6) 
variety (see Additional file 1: references). Some studies also measure shelf height; however, this increases the complexity of data collection. The way variety is measured differs between studies, with some excluding, or including, size, brand, and cultivars (for fresh produce, e.g. royal gala versus Braeburn apples) as different products in variety counts.

Previous studies measuring food availability in-store have often used predetermined food groups and categorized these as healthy or unhealthy. Food groups included have been selected based on various reasons, such as: commonly eaten [8-19], selected by experts $[8,9,11,12,14,17,20,21]$, part of a healthy diet in the region [8-17], contribution to chronic disease or caloric intake [14, 21-26], or selected in previous studies $[8,9,11,12,14,17,20,21,27]$.

Variability in methods previously used to measure food availability has led to inconsistent and conflicting evidence on the effects of consumer retail food environments on purchasing behaviours and diet quality $[28,29]$. The International Network for Food and Obesity/non-communicable diseases Research, Monitoring and Action Support (INFORMAS) is developing methods to measure and benchmark food environments among countries internationally [30]. The INFORMAS retail module outlines an evidence-based framework for global monitoring of both community and consumer retail food environments $[5,30]$. The latter includes measures such as the relative availability, prominence and promotion of healthy versus unhealthy foods in-store. Development of a simple, reliable, and valid indicator of the relative availability of healthy versus unhealthy foods in-store would improve feasibility, allow for comparison between countries and studies, and could be used in further research to examine the relationships between consumer retail food environments and purchasing or dietary behaviors [5].

Therefore, the purpose of this study is to validate a set of simple indicators for measuring relative availability of healthy versus unhealthy foods in-store.

\section{Methods}

Ethics approval for this study was obtained from the University of Auckland Human Participants Ethics Committee (reference number 012330). The study adhered to the principles within the Declaration of Helsinki. No written informed consent from store managers was required but a letter explaining the study was prepared for store managers as a matter of courtesy. Upon entrance of supermarkets, the study methods were explained to the store manager before starting data collection.

For the purposes of this study, the 'gold standard' is defined as the ratio of total availability of healthy foods versus total availability of unhealthy foods in-store. The simple indicators are ratios of availability of a selection of healthy food groups versus availability of a selection of unhealthy food groups in-store. Three nutrient profiling systems were applied to a database of packaged foods available in New Zealand supermarkets and compared to select the healthiest $(n=22)$ and unhealthiest $(n=28)$ food categories for inclusion as part of the 'gold standard'. The shelf length and variety of these 50 food categories were measured in $15 \mathrm{New}$ Zealand supermarkets across three different chains. The construct validity of five different simple indicators for the relative availability of healthy versus unhealthy foods in supermarkets, selected based on literature, was tested against the 'gold standard'. Inter-rater reliability was tested in one supermarket by a second researcher.

\section{Selection of food groups to be included in the 'gold standard'}

Nutritrack is a database comprising food composition data on all packaged food products for sale in four major supermarket chains in New Zealand. Three nutrient profiling models were used to objectively determine which combinations of healthy and unhealthy food groups to include as part of the 'gold standard': the World Health Organisation (WHO) Europe nutrient profile model [31], the New Zealand Ministry of Health ( $\mathrm{MOH})$ Food and Beverage Classification System [32], and the Health Star Ratings system (HSR) [33]. Products with $=<1.5$ stars were considered unhealthy foods and those with $>=4$ stars were considered healthy foods according to the HSR system for the purposes of this study. A total of 13,093 packaged food products were analysed in 2014 and detailed results of the comparison of those nutrient profiling systems have been published previously [34]. To be included as part of the gold standard, food groups needed to have at least $50 \%$ of their products classified as either healthy or unhealthy according to all three nutrient profiling systems. In addition, since specific anomalies (e.g. products getting more or less stars than expected) have been identified with the current HSR system [35], food groups that included $80 \%$ or more healthy or unhealthy products according to both the $\mathrm{WHO}$ and $\mathrm{MOH}$ systems were also included in the 'gold standard' (higher threshold of $80 \%$ since only 2 nutrient profiling systems compared) (Table 1). Sauces, edible oils and spreads are not included in the $\mathrm{MOH}$ system. As to not exclude them from this study, those that included $80 \%$ or more healthy or unhealthy products according to the WHO system were included in the 'gold standard'. The final list of food groups included in the 'gold standard' (Additional file 2: Table S1), based on the comparison of the three nutrient profiling systems, was slightly adjusted after piloting the measurements in two supermarkets, and included 22 healthy and 28 unhealthy food groups, largely in line with the food groups commonly measured in previous research on food availability in-store. 
Table 1 Criteria for food groups to be included as part of the healthy or unhealthy food groups in the gold standard

\begin{tabular}{lll}
\hline Nutrient Profiling System & Healthy food groups & Unhealthy food groups \\
\hline All three systems & $>50 \%$ of products in category meet healthy criteria & $>50 \%$ of products in category meet unhealthy criteria
\end{tabular}

OR

$\mathrm{WHO}$ and $\mathrm{MoH}$ systems $\quad>80 \%$ of products in category met healthy criteria $\quad>80 \%$ of products in category meet unhealthy criteria

OR

Sauces and spreads $\quad>80 \%$ of products in category meet WHO healthy criteria $\quad>80 \%$ of products in category meet WHO unhealthy criteria HSR health star ratings, $\mathrm{MOH}$ Ministry of Health, $W H O$ World Health Organization

Selection of simple indicators to be tested from literature Availability ratios of all possible healthy versus unhealthy food group combinations from the original 50 food categories in the 'gold standard' (Additional file 2: Table S1) would be an unrealistic amount of possibilities to test. Therefore, five simple indicators (Table 2) were selected from previous literature looking at availability of healthy and unhealthy foods in-store, and which included not too many foods for the simple indicators to become impractical. All selected indicators comprised a subset of healthy and unhealthy food groups as included in the 'gold standard'.

\section{Selection of stores}

This study focused on supermarkets as the dominant grocery retailers in New Zealand from which New Zealanders mainly purchase their foods. The two leading supermarket retailers in New Zealand are Progressive Enterprises and FoodStuffs, which together make up more than $90 \%$ of the market share according to Euromonitor [36]. Foodstuffs owns the supermarket chains Pak'nSave and New World, which have 53 and 139 stores across New Zealand and a $54 \%$ value share. Progressive Enterprises owns the chain Countdown, which has 183 supermarkets in New Zealand and a $38 \%$ value share. A convenience sample of 15 supermarkets in Auckland, New Zealand, was selected, across the three major chains (Countdown, Pak'nSave, New World) of medium to large supermarkets, defined as supermarkets with three or more cash registers. The areas in which these supermarkets were located covered a range of different socioeconomic deprivation levels. One supermarket manager declined participation because he didn't want pictures to be taken within the supermarket. This supermarket was replaced by another one from the same chain.

\section{Data collection}

Data collection was carried out between October 2015 and January 2016 (excluding December). The cumulative linear shelf length of and variety within the 50 different food groups included in the 'gold standard' (and simultaneously for the subset of food groups included within each of the five indicators) were measured by supermarket area.

Supermarket areas are based on the nine locations used in the validated Go Promo tool [37], and include: outside, entrance, endcaps front, endcaps back, aisles, edge, islands, checkouts side and checkouts end. The outside area was excluded for obvious reasons.

Linear shelf length of the different food groups was measured in meters using a laser instrument (Bosch PLR50,

Table 2 Selected simple indicators for measuring the relative availability of healthy versus unhealthy foods in supermarkets

\begin{tabular}{ll}
\hline Indicator & Healthy and unhealthy food groups included \\
\hline 1 & $\begin{array}{l}\text { fresh and frozen fruit and vegetables (including packaged) } \\
\text { vs. soft drinks, crisps and snacks, sweet biscuits, cakes and } \\
\text { slices, confectionery }\end{array}$ \\
& fresh fruit and vegetables (including packaged) vs. soft drinks \\
& and energy drinks \\
& fresh fruit and vegetables (including packaged) vs. soft drinks, \\
crisps and snacks, confectionery
\end{tabular}

$4 \quad$ fresh and frozen fruit and vegetables (including packaged) vs. soft drinks, energy drinks, crisps and snacks, sweet biscuits, confectionery

5 frozen fruit and vegetables vs. soft drinks, energy drinks, crisps and snacks

Rationale

Based on food categories used in previous studies by Farley et al 2009 [38], Rose et al 2009 [23], Miller 2012 [24], and Bodor et al 2013 [39]. These studies did include canned fruit and vegetables but these were not included in the 'gold standard' in this study, so excluded.

These food groups represent the most commonly included healthy and unhealthy food categories in previous research on food availability in-store

The food groups in this indicator are those used in the Australian study by Cameron et al 2013 [40]. Fresh fruit and vegetables were used by 15 previous studies as the only healthy food items measured. Soft drinks, crisps, and confectionery were the three most commonly measured unhealthy foods in previous studies.

Similar to indicator 1 but excludes the cakes and slices to improve feasibility of measurements in-store.

The included food categories were all common inclusions as healthy or unhealthy foods in previous studies. Excludes fresh fruit and vegetables as these products require more complex measurements to be performed in-store (e.g. measuring bins, no clear shelves). 
with measurement accuracy to $2 \mathrm{~mm}$ ) either along the shelf or along the floor in front of the shelf. The number of shelves (of equal measured length) on which the food category was displayed was also recorded and multiplied by the linear shelf length to obtain the cumulative shelf length for each food category. If shelf length for a particular food category was different across different shelves, the shelf length was measured and recorded for each shelf separately and then summed to produce a total shelf length. For shelving units that did not have a physical shelf (e.g. units with hanging confectionery), rows of hanging products were counted as a single shelf. Displays that contained multiple rows of different products (for example. deli meats or dividers between frozen food) were also be counted as multiple 'shelves' in this way. Measurement of islands/freestanding bins was performed by measuring the exposed sides from which customers could pick products, as consistent with previous studies $[23,38]$. For round freestanding bins, the diameter was measured and circumference calculated using $2 \pi \mathrm{r}$. A paper data collection sheet was used to record the shelf length measurements.

In addition to measuring shelf length, photos of shelf sections including the different products were taken, including details on front-of-pack and price tags with names of products to aid in identifying different varieties. The photos were then sorted into the different healthy and unhealthy food categories and the number of product varieties in each was counted using a hand held counter. Variety was defined as the total number of different food products available in the supermarket within a certain food category. Two different counts of variety were used:

1. Variety including different sizes, flavours, and variations such as fair trade/organic, countries of origin (e.g. Australian versus American oranges), and cultivars (e.g. royal gala versus Braeburn apples) as different products.

2. Same as 1. but excluding different sizes of the same product, i.e. different sizes are counted only once.

All measurements were conducted by a single researcher following a standard protocol. The researcher was trained (including on the inclusions and exclusions for each of the 50 food groups to be measured) and pilot tested the protocol in two supermarkets before starting actual data collection. For some of the food groups included, shelf length was not easily measurable in the supermarket, as food items in those groups were not placed together on the shelves. For this reason, some food groups were either further divided or combined into different sub groups that were more feasible for measurement after the pilot test. For the purposes of calculating inter-rater reliability, one supermarket was assessed by a second researcher on the same day.
Cumulative shelf length of and variety within all 50 food categories were compared between both researchers.

\section{Statistical analysis}

Data was analysed using IBM SPSS statistical software version 23 (IBM Corp, Armonk, NY, USA 2015). Interrater reliability was tested using intra-class correlations (ICCs). In addition, the absolute difference in cumulative shelf length and variety counts between the two researchers was calculated, as well as the difference as a percentage of the average shelf length/variety.

The construct validity of the five simple indicators for the relative availability of healthy versus unhealthy foods in supermarkets was tested through: 1) a Wilcoxon signed rank test to assess the difference between each simple indicator and the 'gold standard', and 2) Spearman rank correlation coefficients to assess associations between the 'gold standard' and each simple indicator.

\section{Results}

Table 3 shows the average cumulative linear shelf length of food groups categorised as healthy and unhealthy, as well as the ratio of cumulative linear shelf length of healthy vs. unhealthy foods. In addition, the number of varieties in each category is also presented. A consistently low ratio of healthy to unhealthy products is evident across all three measures of food availability and ranges from 0.2 to 0.4 . There is also considerable variation across the different supermarket chains, especially for shelf length ratios, although the sample size for such comparison is low. When excluding check-outs and end-of-aisle endcaps from the measurements of cumulative shelf length (products in these locations tend to change more quickly than in other supermarket locations and check-outs are often harder to measure in view of customers lining up), the ratio of cumulative linear shelf length for healthy vs. unhealthy foods increases. Shelf length ratio did not appear to be related to variety ratio.

All three measures (shelf length, variety measures 1 and 2) showed very good inter-rater reliability with all three ICCs $=0.99$, showing near perfect agreement. The largest differences in cumulative linear shelf length measured between both researchers were found for Asian sauces, coconut cream and milk, cereal bars, sugars, reduced fat powdered milks, plain noodles, plain couscous, breakfast biscuits, chilled seafood, dried vegetables and legumes, and unsalted nuts, representing 11 of the 50 food categories measured (data not shown).

Table 4 shows the results of the comparison between the five different simple indicators and the 'gold standard' of relative availability of total healthy versus total unhealthy foods in supermarkets. Shelf length ratio indicators $1,2,3,4$ are all significantly associated with the gold standard $(\rho=0.70-0.75)$. Both shelf length ratio indicators 
Table 3 Cumulative linear shelf length of and variety within healthy and unhealthy foods (gold standard) in supermarkets

\begin{tabular}{|c|c|c|c|c|c|c|}
\hline & \multicolumn{2}{|c|}{ Chain A ( $n=5$ stores) } & \multicolumn{2}{|c|}{ Chain B ( $n=5$ stores) } & \multicolumn{2}{|c|}{ Chain C ( $n=5$ stores) } \\
\hline & Average & Standard Deviation & Average & Standard Deviation & Average & Standard Deviation \\
\hline \multicolumn{7}{|l|}{ Cumulative linear shelf length } \\
\hline TOTAL HEALTHY shelf length (m) & 437.0 & 142.7 & 230.3 & 40.3 & 335.1 & 60.2 \\
\hline TOTAL UNHEALTHY shelf length $(\mathrm{m})$ & 1151.0 & 308.6 & 909.0 & 218.3 & 1907.5 & 400.5 \\
\hline Ratio total healthy: total unhealthy shelf length & 0.38 & 0.06 & 0.27 & 0.11 & 0.18 & 0.02 \\
\hline \multicolumn{7}{|l|}{$\begin{array}{l}\text { Cumulative linear shelf length (excluding endcaps } \\
\text { and check-outs) }\end{array}$} \\
\hline TOTAL HEALTHY shelf length (m) & 422.8 & 134.7 & 221.0 & 32.6 & 328.7 & 59.0 \\
\hline TOTAL UNHEALTHY shelf length (m) & 998.4 & 299.5 & 791.2 & 195.1 & 1666.6 & 337.1 \\
\hline Ratio total healthy: total unhealthy shelf length & 0.43 & 0.06 & 0.30 & 0.12 & 0.20 & 0.02 \\
\hline \multicolumn{7}{|l|}{$\begin{array}{l}\text { Variety } 1 \text { (including different package sizes as } \\
\text { different products) }\end{array}$} \\
\hline TOTAL HEALTHY varieties & 675.0 & 146.6 & 550.0 & 23.9 & 712.6 & 54.1 \\
\hline TOTAL UNHEALTHY varieties & 2842.6 & 516.9 & 2093.6 & 61.8 & 2571.2 & 348.9 \\
\hline Ratio total healthy: total unhealthy varieties & 0.24 & 0.02 & 0.26 & 0.01 & 0.28 & 0.03 \\
\hline \multicolumn{7}{|l|}{$\begin{array}{l}\text { Variety } 2 \text { (excluding different package sizes as } \\
\text { different products) }\end{array}$} \\
\hline TOTAL HEALTHY varieties & 578.6 & 134.0 & 488.4 & 21.3 & 633.2 & 58.5 \\
\hline TOTAL UNHEALTHY varieties & 2397.0 & 465.8 & 1799.0 & 65.0 & 2157.6 & 316.7 \\
\hline Ratio total healthy: total unhealthy varieties & 0.24 & 0.02 & 0.27 & 0.01 & 0.30 & 0.03 \\
\hline
\end{tabular}

1 and 4 show a non-significant difference $(p>0.05)$ compared to the 'gold standard' as well as a significant association with the gold standard $(p<0.05)$. In regards to the variety ratios, the indicators perform better when different sizes are not included in the variety measure as different products. Variety ratio indicators $1,2,4$ and 5 are all significantly associated with the gold standard $(\rho=0.56-$ $0.75)$. Only indicator 1 and 5 are both significantly associated with the gold standard, as well as not significantly different from the gold standard (Table 4).

The differences between the indicators and the gold standard also showed some variation among different supermarket chains. Shelf length ratio indicators 1 and 4 showed the smallest difference from the 'gold standard' across all three brands. Indicator 2 showed the largest differences with the 'gold standard' across all three chains and all three measures (shelf length, variety 1 and variety 2) (data not shown).

\section{Discussion}

This study validated five indicators of relative availability of healthy versus unhealthy foods in-store against a gold standard. Healthy and unhealthy food availability were assessed by measuring both cumulative linear shelf length, as well as variety. These are two different concepts, as shelf length indicates the shelf space taken up by certain food groups regardless of the variety of foods within those food groups, while variety indicates the different choices available within each food group, regardless of the shelf space taken up by those food groups.

Cumulative linear shelf length was shown to be a more sensitive measure for food availability in supermarkets than variety. The measures of shelf length are also less time consuming than those for variety, and more acceptable to supermarket retailers who expressed some concerns about taking pictures of shelf sections in-store. A limitation of the shelf length ratio measure is that some food products are not placed on a physical shelf (e.g. hanging confectionary or fruit in freestanding bins) and methods were slightly adapted to be able to measure shelf length for those products.

The variety ratios of healthy versus unhealthy food products differed less dramatically between store types compared to shelf length ratios of healthy versus unhealthy foods. The variety measures would be less practical in larger studies due to the time burden and difficulties around permissions for taking pictures in-store.

To measure validity of the five shelf length ratio indicators against a gold standard, we evaluated both correlations between indicators and the 'gold standard', as well as the difference between indicators and the 'gold standard'. For New Zealand supermarkets specifically, the 'gold standard' includes all healthy and unhealthy foods in-store and thus measures the relative availability of healthy versus unhealthy foods in-store adequately. Therefore, for New Zealand supermarkets, shelf length indicators 1 and 


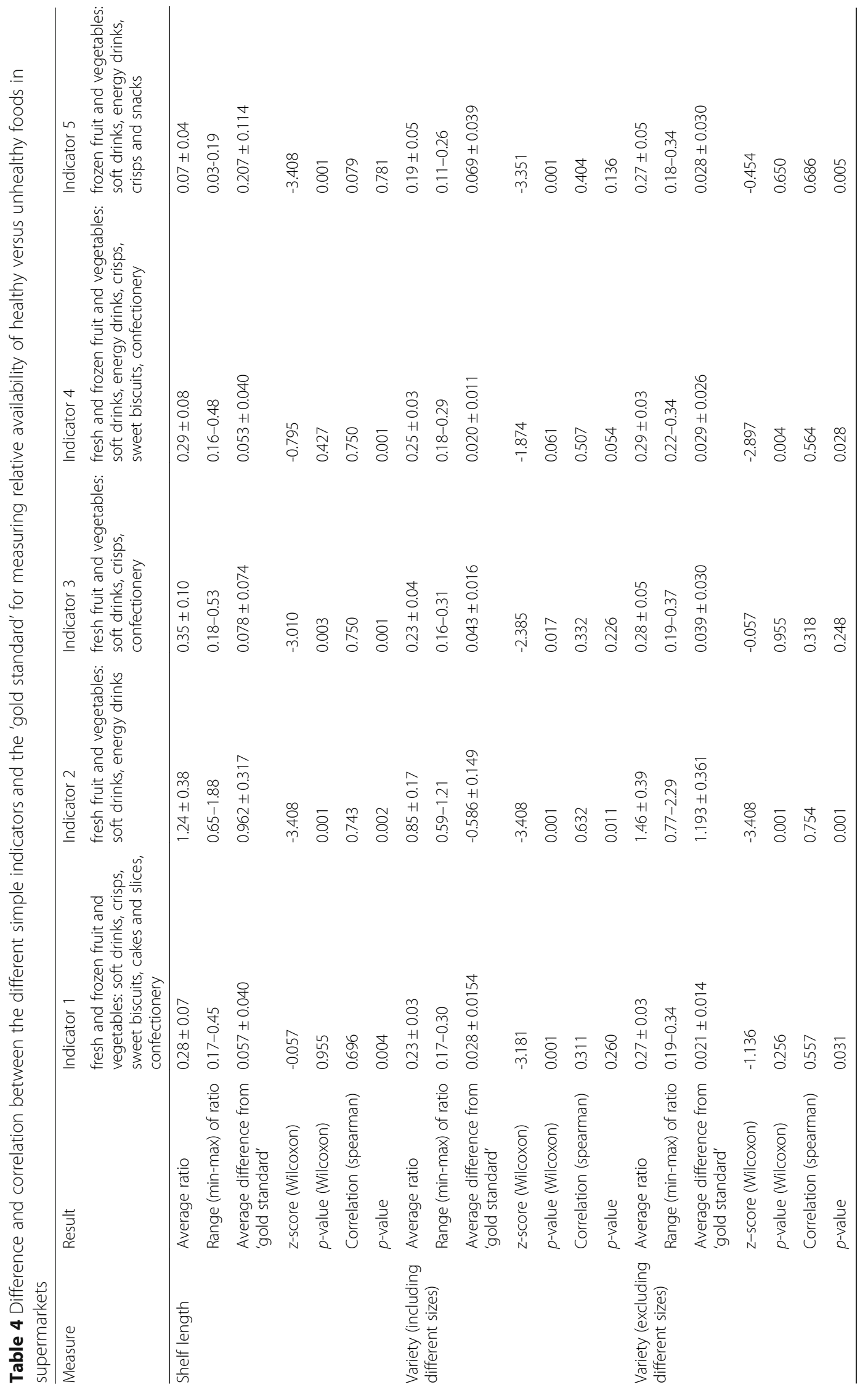


4 show the most potential as simple and valid indicators of in-store availability of healthy versus unhealthy foods. These indicators show a non-significant difference from the 'gold standard' indicator for shelf length as well as a significant correlation with the gold standard. Both of these indicators would be much faster and easier to measure in-store food availability than the 'gold standard' and still be similar to the 'gold standard' ratio of healthy versus unhealthy foods in each store. Indicator 4 is further preferred in view of the difficulty of measuring cakes and slices in-store (as they are found in many different locations across the store) and thus has a higher feasibility for monitoring. Therefore, indicator 4 (cumulative linear shelf length of fresh and frozen fruit and vegetables versus soft drinks and energy drinks, crisps and snacks, sweet biscuits and confectionery) would be the best indicator to use in future research and monitoring as a valid indicator of the availability of healthy and unhealthy foods in New Zealand supermarkets.

However, for other countries, settings and contexts, four out of the five shelf length ratio indicators could be used in future research and monitoring since they were all significantly correlated to the gold standard and correlations were very similar. The difference between the indicators and the gold standard, as measured in this study, is less relevant in this case since in other countries and contexts the foods available in the food groups as part of the indicators may differ, as well as the shelf length they take up in the supermarkets. In addition, in other contexts researchers may want to use different nutrient profiling systems to determine the healthy and unhealthy food groups as part of the gold standard. Therefore, in other countries and contexts, additional validation studies using those four shelf length ratio indicators are recommended.

The findings of this study are largely consistent with previous research using similar indicator food groups that showed shelf length dedicated to unhealthy food to be higher than the shelf length allocated to healthy foods in supermarkets $[23,38]$. Using the 'gold standard' measurement, the ratios calculated in this study varied between 0.18 and 0.38 , depending on supermarket chain.

\section{Feasibility}

Performing data collection for the 'gold standard' presented multiple challenges and took on average eight hours to complete per supermarket, including shelf length measurements, photo taking, and variety counts afterwards using the photos. Management of pictures and counting of variety after data collection in the supermarkets took up to five hours, as on average 800 photos were taken at each supermarket and an average of 2500 unhealthy and 650 healthy varieties counted in each store. Measuring the gold standard was time consuming as some products were found in many locations around the supermarket on small sections of shelf, which meant many measurements were made to collect the total cumulative linear shelf length of the food group. This was particularly the case for food groups such as unsalted nuts, dried vegetables and legumes, confectionary, cakes muffins and pastries, table sauces, and meal based sauces and marinades. It is important for data collectors to have good knowledge on inclusion and exclusion criteria for foods within each of the 50 food groups included as part of the gold standard. In addition, the pictures need to be of sufficient resolution to easily read the product's price tags, which were useful in distinguishing a product as a new variety or size (as they typically contained a detailed description and size of the product).

The indicator selected for New Zealand supermarkets based on the results from this study (cumulative linear shelf length of fresh and frozen fruit and vegetables versus soft drinks and energy drinks, crisps and snacks, sweet biscuits and confectionery) takes about one hour to measure in-store and no pictures need to be taken, which makes it a feasible measure for use in larger studies. Indicator 2 and 3 include even fewer food groups and may thus take even less time to measure in-store, while indicator 1 is a bit more time consuming due to the cakes and slices being located in many different places in-store.

\section{Strengths and limitations}

This study is the first of its kind to validate a series of simple indicators for the relative availability of healthy versus unhealthy foods in-store to improve feasibility and standardization of monitoring efforts, such as those by INFORMAS [5]. We used relevant international literature and nutrient profiling systems to guide selection of food availability measures, food categories as part of the gold standard and simple indicators using different combinations of healthy and unhealthy food categories. This study provides valuable information about the construct validity and feasibility of a series of indicators for the relative availability of healthy versus unhealthy foods in-store for use in future research. The advantage of using a ratio rather than absolute measures is that it also minimizes the effects of store size, allowing for comparison between stores.

The study included a few limitations. The Nutritrack database and HSR nutrient profiling system only cover packaged foods with a Nutrition Information Panel, so assumptions had to be made based on packaged versions of foods for inclusion or exclusion (e.g. packaged fruit and vegetables). Another limitation of this study was that supermarkets measured in October-November already had many Christmas themed confectionery, cakes, and sweet biscuits. In addition, the supermarkets visited in the January period (when Christmas stock was expected to no longer be on shelves) still had some leftover Christmas 
period stock as well as some Easter confectionery themed products in store already. This may have influenced the shelf length and variety counts of unhealthy products from these supermarkets.

The study only included supermarkets and could be repeated to validate in-store measures for other types of outlets, especially in areas where there may not be large supermarkets available. For example, smaller conveniencetype stores are more commonly found rurally and would be important to include as part of an assessment of in-store food availability. Other measures might however need to be developed for small stores, as they do not have the full range of products available such as in supermarkets.

\section{Implications for further research and monitoring}

Four out of five shelf length ratio indicators of relative availability of healthy and unhealthy foods in supermarkets tested in this study can be used for future research and monitoring, but additional validation studies will be required in other settings, especially in low and middle income countries. For New Zealand specifically, the linear cumulative shelf length allocated to fresh and frozen fruit and vegetables versus soft drinks and energy drinks, crisps, sweet biscuits and confectionery provides the best indicator for the availability of healthy versus unhealthy foods in supermarkets. Use of this indicator would provide a valid, consistent tool to collect data in a large number of supermarkets and settings, to both monitor food availability and assess its effects on consumer purchases. When using the indicators in future research and monitoring, it is important to consider the frequency and period of measurements (seasonality, frequency of changes of products within stores), sampling of supermarkets and duration of data collection. Both the gold standard and the indicators included all locations in the supermarket, but it needs to be acknowledged that the foods in some locations (endcaps and checkouts) may change more quickly than in other supermarket locations (e.g. aisles). However, excluding these locations from the study is not recommended as 1) those are among the most prominent locations in the supermarket, 2) this would not represent an adequate measure of availability and 3) it is likely that, such as in this study, the ratios on the relative availability of healthy versus unhealthy foods would increase as unhealthy foods are predominant in those locations. The indicator, similar as the gold standard, showed large variety across stores and chains in New Zealand, which means sufficient supermarkets would need to be included in a sample to be representative of the healthiness of the instore retail food environment at national or regional level.

\section{Conclusions}

Four out of five shelf length ratio indicators tested in this study could be used for future research and monitoring, but additional testing and validation in other settings is recommended. Ratio of cumulative linear shelf length of fresh and frozen fruit and vegetables to soft drinks and energy drinks, crisps and snacks, sweet biscuits and confectionery provides a simple and feasible indicator of the in-store availability of healthy versus unhealthy foods in New Zealand supermarkets. Consistent use of those shelf length ratio indicators in future research and monitoring would enhance comparability of food availability between different countries and studies, and strengthen the research linking the in-store food environment with diet and obesity.

\section{Additional files}

Additional file 1: Supplementary references of previous studies measuring food availability in-store. (PDF $146 \mathrm{~kb}$ )

Additional file 2: Table S1. List of the 22 healthy and 28 unhealthy food groups part of the 'gold standard' as derived from the comparison of three nutrient profiling systems. (DOCX $15.5 \mathrm{~kb}$ )

\section{Abbreviations}

HSR: Health star rating; ICC: Intra-class correlations; INFORMAS: International network for food and obesity research, monitoring and action support; $\mathrm{MOH}$ : Ministry of health; WHO: World Health Organization

\section{Acknowledgements \\ None}

\section{Funding}

The study was funded by the Health Research Council of New Zealand. The funder had no role in the design of the study and collection, analysis, and interpretation of data and in writing the manuscript.

\section{Authors' contributions}

SV and CM designed the study, TM collected the data, TM and SV analysed and interpreted the data. SV wrote the manuscript and all authors critically commented on draft versions of the manuscript. All authors read and approved the final manuscript.

\section{Availability of data and materials}

The tools (e.g. data collection form), datasets used and/or analysed during the current study available from the corresponding author on reasonable request.

\section{Competing interests}

The authors declare that they have no competing interests.

\section{Consent for publication}

Not applicable.

\section{Ethics approval and consent to participate}

Ethics approval for this research was obtained from the University of Auckland Human Participants Ethics Committee (reference number 012330). No written informed consent from store managers was required but a letter explaining the study was prepared for store managers as a matter of courtesy. Upon entrance of supermarkets, the study methods were explained to the store manager before starting data collection.

\section{Publisher's Note}

Springer Nature remains neutral with regard to jurisdictional claims in published maps and institutional affiliations. 


\section{Author details}

'School of Population Health, The University of Auckland, Private bag 92019. Glen Innes, New Zealand. ${ }^{2}$ National Institute for Health Innovation, The University of Auckland, Auckland, New Zealand.

Received: 28 November 2016 Accepted: 12 April 2017

Published online: 26 April 2017

\section{References}

1. Ng M, Fleming T, Robinson M, Thomson B, Graetz N, Margono C, Mullany EC, Biryukov S, Abbafati C, Abera SF, et al. Global, regional, and national prevalence of overweight and obesity in children and adults during 19802013: a systematic analysis for the global burden of disease study 2013. Lancet. 2014;384(9945):766-81.

2. Vandevijvere $\mathrm{S}$, Chow CC, Hall KD, Umali E, Swinburn BA. Increased food energy supply as a major driver of the obesity epidemic: a global analysis. Bull World Health Organ. 2015;93(7):446-56.

3. Lehnert T, Sonntag D, Konnopka A, Riedel-Heller S, Konig HH. The long-term cost-effectiveness of obesity prevention interventions: systematic literature review. Obes Rev. 2012;13(6):537-53.

4. Glanz K, Sallis JF, Saelens BE, Frank LD. Healthy nutrition environments: concepts and measures. Am J Health Promot. 2005;19(5):330-3. ii.

5. Ni Mhurchu C, Vandevijvere S, Waterlander W, Thornton LE, Kelly B, Cameron AJ, Snowdon W, Swinburn B. Informas: Monitoring the availability of healthy and unhealthy foods and non-alcoholic beverages in community and consumer retail food environments globally. Obes Rev. 2013;14 Suppl 1: 108-19.

6. Engler-Stringer R, Le H, Gerrard A, Muhajarine N. The community and consumer food environment and children's diet: a systematic review. BMC Public Health. 2014;14:522.

7. Holsten JE. Obesity and the community food environment: a systematic review. Public Health Nutr. 2008;12(3):397-405.

8. Martins PA, Cremm EC, Leite FH, Maron LR, Scagliusi FB, Oliveira MA Validation of an adapted version of the nutrition environment measurement tool for stores (NEMS-S) in an urban area of Brazil. J Nutr Educ Behav. 2013;45(6):785-92.

9. Gloria CT, Steinhardt MA. Texas nutrition environment assessment of retail food stores (TxNEA-S): development and evaluation. Public Health Nutr. 2010;13(11):1764-72.

10. Andreyeva T, Blumenthal DM, Schwartz MB, Long MW, Brownell KD. Availability and prices of foods across stores and neighborhoods: the case of New Haven, Connecticut. Health Aff. 2008;27(5):1381-8.

11. Lee-Kwan SH, Kumar G, Ayscue P, Santos M, McGuire LC, Blanck HM, Nua MT. Healthful food availability in stores and restaurants - american samoa, 2014. MMWR Morb Mortal Wkly Rep. 2015;64(10):276-8.

12. Gustafson AA, Sharkey J, Samuel-Hodge CD, Jones-Smith J, Folds MC, Cai J, Ammerman AS. Perceived and objective measures of the food store environment and the association with weight and diet among low-income women in North Carolina. Public Health Nutr. 2011;14(6):1032-8.

13. Hillier A, McLaughlin J, Cannuscio CC, Chilton M, Krasny S, Karpyn A. The impact of WIC food package changes on access to healthful food in 2 lowincome urban neighborhoods. J Nutr Educ Behav. 2012;44(3):210-6.

14. Franco M, Diez-Roux AV, Nettleton JA, Lazo M, Brancati F, Caballero B, Glass T, Moore LV. Availability of healthy foods and dietary patterns: the multiethnic study of Atherosclerosis. Am J Clin Nutr. 2009;89(3):897-904.

15. Bertoni AG, Foy CG, Hunter JC, Quandt SA, Vitolins MZ, Whitt-Glover MC. A multilevel assessment of barriers to adoption of dietary approaches to stop hypertension (DASH) among African Americans of low socioeconomic status. J Health Care Poor Underserved. 2011;22(4):1205-20.

16. Gantner LA, Olson CM, Frongillo EA, Wells NM. Prevalence of nontraditional food stores and distance to healthy foods in a rural food environment. J Hunger and Environ Nutr. 2011;6(3):279-93.

17. Olendzki BC, Procter-Grey E, Wedick NM, Patil V, Zheng H, Kane K, Land T, Li W. Disparities in Access to Healthy and Unhealthy Foods in Central Massachusetts: Implications for Public Health Policy. J Am Coll Nutr. 2015;34(2):150-8.

18. Lear SA, Gasevic D, Schuurman N. Association of supermarket characteristics with the body mass index of their shoppers. Nutr J. 2013;12:117.

19. Stroebele N, Dietze P, Tinnemann P, Willich SN. Assessing the variety and pricing of selected foods in socioeconomically disparate districts of Berlin Germany. J Public Health (Oxf). 2011;19(1):23-8.
20. Horacek TM, Erdman MB, Reznar MM, Olfert M, Brown-Esters ON, Kattelmann KK, Kidd T, Koenings M, Phillips B, Quick V, et al. Evaluation of the food store environment on and near the campus of 15 postsecondary institutions. Am J Health Promot. 2013;27(4):e81-90.

21. Rimkus L, Powell LM, Zenk SN, Han E, Ohri-Vachaspati P, Pugach O, Barker DC, Resnick EA, Quinn CM, Myllyluoma J, et al. Development and reliability testing of a food store observation form. J Nutr Educ Behav. 2013;45(6):540-8.

22. Black C, Ntani G, Inskip H, Cooper C, Cummins S, Moon G, Baird J. Measuring the healthfulness of food retail stores: variations by store type and neighbourhood deprivation. Int. 2014;11:69.

23. Rose D, Hutchinson PL, Bodor JN, Swalm CM, Farley TA, Cohen DA, Rice JC. Neighborhood food environments and Body Mass Index: the importance of in-store contents. Am J Prev Med. 2009;37(3):214-9.

24. Miller C, Bodor JN, Rose D. Measuring the food environment: a systematic technique for characterizing food stores using display counts. J Environ Public Health. 2012;2012:707860.

25. Lee RE, Heinrich KM, Medina AV, Regan GR, Reese-Smith JY, Jokura Y, Maddock JE. A picture of the healthful food environment in two diverse urban cities. Environ Health Insights. 2010;4:49-60.

26. Block D, Kouba J. A comparison of the availability and affordability of a market basket in two communities in the Chicago area. Public Health Nutr. 2006:9(7):837-45.

27. Chacon V, Letona P, Barnoya J. Child-oriented marketing techniques in snack food packages in Guatemala. BMC Public Health. 2013;13:967.

28. Glanz K, Sallis JF, Saelens BE, Frank LD. Nutrition environment measures survey in stores (NEMS-S): development and evaluation. Am J Prev Med. 2007;32(4):282-9.

29. Gustafson A, Hankins S, Jilcott S. Measures of the consumer food store environment: a systematic review of the evidence 2000-2011. J Community Health. 2012;37(4):897-911.

30. Swinburn B, Sacks G, Vandevijvere S, Kumanyika S, Lobstein T, Neal B, Barquera S, Friel S, Hawkes C, Kelly B, et al. INFORMAS (international network for food and obesity/non-communicable diseases research, monitoring and action support): overview and key principles. Obes Rev. 2013;14 Suppl 1:1-12.

31. World Health Organisation. WHO Regional Office of Europe nutrient profile model. In. Copenhagen, Denmark: The World Health Organization Europe; 2015.

32. Ministry of Health. Food and Beverage Classification System for Years 1-13 User Guide. In. Wellington, New Zealand: Ministry of Health; 2007.

33. Guide for industry to the Health Star Rating Calculator (HSRC) [http://healthstarrating.gov.au/internet/healthstarrating/publishing.nsf/ Content/E380CCCA07E1E42FCA257DA500196044/\$File/Guide\%20for\% 20lndustry\%20to\%20the\%20HSR\%20Calculator\%20v5\%20June\%202016.pdf]. Accessed 15 Nov 2016.

34. Mhurchu CN, Mackenzie T, Vandevijvere S. Protecting New Zealand children from exposure to the marketing of unhealthy foods and drinks: a comparison of three nutrient profiling systems to classify foods. N Z Med J. 2016:129(1441):41-53.

35. Fact check: Do higher food star ratings always mean a healthier choice? [http://www.abc.net.au/news/2015-09-08/fact-check-health-star-ratings-onfoods/6518996]. Accessed 15 Nov 2016.

36. Euromonitor International. Grocery Retailers in New Zealand. 2015.

37. Kerr J, Sallis JF, Bromby E, Glanz K. Assessing reliability and validity of the GroPromo audit tool for evaluation of grocery store marketing and promotional environments. J Nutr Educ Behav. 2012;44(6):597-603.

38. Farley TA, Rice J, Bodor JN, Cohen DA, Bluthenthal RN, Rose D. Measuring the food environment: shelf space of fruits, vegetables, and snack foods in stores. J Urban Health. 2009;86(5):672-82.

39. Bodor JN, Hutchinson PL, Rose D. Car ownership and the association between fruit and vegetable availability and diet. Prev Med. 2013;57(6):903-5.

40. Cameron AJ, Thornton LE, McNaughton SA, Crawford D. Variation in supermarket exposure to energy-dense snack foods by socio-economic position. Public Health Nutr. 2013;16(7):1178-85. 